\title{
The A-VEDAM Model For Approaching Vehicle Exterior Design
}

\author{
Hiroki Asami, Aoyama Gakuin University, Japan \\ Hideaki Owada, Aoyama Gakuin University, Japan \\ Yuka Murata, Aoyama Gakuin University, Japan \\ Shouhei Takebuchi, Aoyama Gakuin University, Japan \\ Kakuro Amasaka, Aoyama Gakuin University, Japan
}

\begin{abstract}
The exterior design of a vehicle is an important subjective factor in customer purchase decisions today, and it is critical that designs match customer lifestyles. This paper introduces A-VEDAM (Amasakalab's Vehicle Exterior design Approach Model), a model for approaching exterior design in a way that harmonizes the external form (profile) and color of the vehicle to meet the demands of the coming years. The development of the A-VEDAM focuses on the fact that more young women are getting driver's licenses and purchasing cars.
\end{abstract}

Keywords: exterior design; A-VEDAM model; exterior form and color; young women

\section{INTRODUCTION}

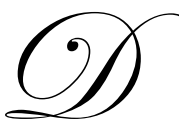

espite reports that young people are reducing their use of vehicles, there is an extremely high level of latent need among young women who are increasingly getting driver's licenses and purchasing vehicles. This paper provides a model for approaching the process of creating new auto designs that will fulfill these latent needs.

Even as customer needs in general become increasingly diverse, the preferences of young women are thought to be particularly varied and difficult to pinpoint. Today's women place priority on vehicle color when purchasing a vehicle, and it has been shown that these color choices have strong links to clothing and fashion.

The authors have thus concluded that creating the vehicle designs that women want requires matching women's preferences in terms of lifestyle and fashion (clothing). In other words, it is essential to generate a sense of "customer delight". Previous approaches have placed priority on the form of the vehicle design, with color treated as an afterthought. However, it is the harmony between the shape and the color of the vehicle that can give customers that feeling of delight.

A crowd-watching study was done based on these conclusions, and it was found that the vehicles that are attractive to people living both in urban and suburban areas are those that seem stylish or offer a sense of luxury. These results were used to create a subjective values chart grouping preferences into different categories based on "image words".

Colors were then selected by pairing tones that evoked the sense of these four image words with fashion designs that typified an "elegant" look. Next, in order to bridge the gap between customer evaluations and actual vehicle designs, 3D-CAD software was used to generate vehicle designs that gave a unified sense of form and color.

\section{BACKGROUND AND PRIOR RESEARCH}

Businesses that continue to grow in today's world are those that carry out quality management from a customer-first perspective, aggressively work to pinpoint customer desires, and reflect these approaches in their 
product development processes. However, even among successful businesses, the approach that product planners and designers take to capturing the mindset of their customers and reflecting it in actual products (in other words, their method of generating the ideas that guide the design process) is typically an unspoken one based largely on personal skill and experience. As a result, whether or not the designers did quality work depends on the strength of sales in the market, and procedures that can be used for later work are not given sufficient attention. Under this system, it is easy for the emphasis to be placed on an unspoken procedure.

Under this system, success is a result of good luck (or failure of bad luck), and the current approach to business processes depends on every individual's unique way of doing their work and the "rules of thumb" that they follow. This precarious situation creates a dilemma for companies that wish to increase their chances of success in the future. A new strategic product design method-a method that creates desires and supports the generation of ideas during strategic product development-must therefore be developed to revamp the business processes extending from product planning to design. These processes must be incorporated into a "designing" stage, and their effectiveness demonstrated.

Much prior research has focused on the proportions and form of vehicle bodies or on proposing design concepts. However, in order to ensure that future vehicle development truly takes direct customer feedback into consideration, designers must work to match customer lifestyles. To this end, the authors have chosen to focus on young women, whose needs are thought to be particularly varied and difficult to pinpoint even as customer needs in general become increasingly diverse. What today's women place priority on when purchasing a vehicle is the color, and it has been shown that these color choices have strong links to clothing and fashion.

The authors have thus concluded that creating the vehicle designs that women want requires matching women's preferences in terms of lifestyle and fashion (clothing). In other words, it is essential to generate a sense of "customer delight". Previous approaches have placed priority on the form of the vehicle design, with color treated as an afterthought. However, this study proposes that it is the harmony between the shape and the color of the vehicle that can give customers that feeling of delight. A shape and design framework consisting of three factors (profile, shape/form, and surface) was identified. Interviews revealed that the profile of a vehicle was what attracted attention instantly or from far away, so this is the design aspect that was highlighted.

\section{NECESSITY OF FORM NUMERIC REPRESENTATION BY CAD}

In order to visualize the degree of influence to sensitivity of the customer due to the change of the form, digitalization of the form is indispensable. CAD (Computer Aided Design) the software is utilized in this research (1) as an expedient in order to solve the digitalization of the form. As the advantage of using the CAD software, "Digitalization of the form (parametrization)" it can do with the invocation of the CAD software whose numerical definition of form is possible.

Because such as front side rear, it is verification possible from all angles, sensitivity of the customer to collate, it is possible, We can list the fact that among other things those where CAD is used as the tool which expresses the form the case of the modeling become main current even with design process of present condition. Furthermore, in this research "CATIA V5" is used as CAD software.

\section{OVERVIEW OF THE A-VEDAM MODEL FOR APPROACHING VEHICLE EXTERIOR DESIGN}

As mentioned above, customer delight is achieved through a harmony of form and color. There are several major research issues that arise in the process of promoting our major theme; namely, creating a method to support the generation of vehicle design ideas that evoke a subjective response in customers.

The A-VEDAM model for approaching auto exterior design shown in Figure 1 was developed in an attempt to resolve these issues. In step 1, a target is selected for crowd watching and interviews, and the importance of the profiles and colors preferred by women is identified. In step 2, a subjective survey sheet is created to identify women's preferences, and given groups of customers divided by preference. Then, collage boards are made outlining the lifestyles of each group. In order to identify exterior designs that match the lifestyles indicated, a color analysis is carried out in step 3 while a profile analysis is simultaneously carried out in step 4. 


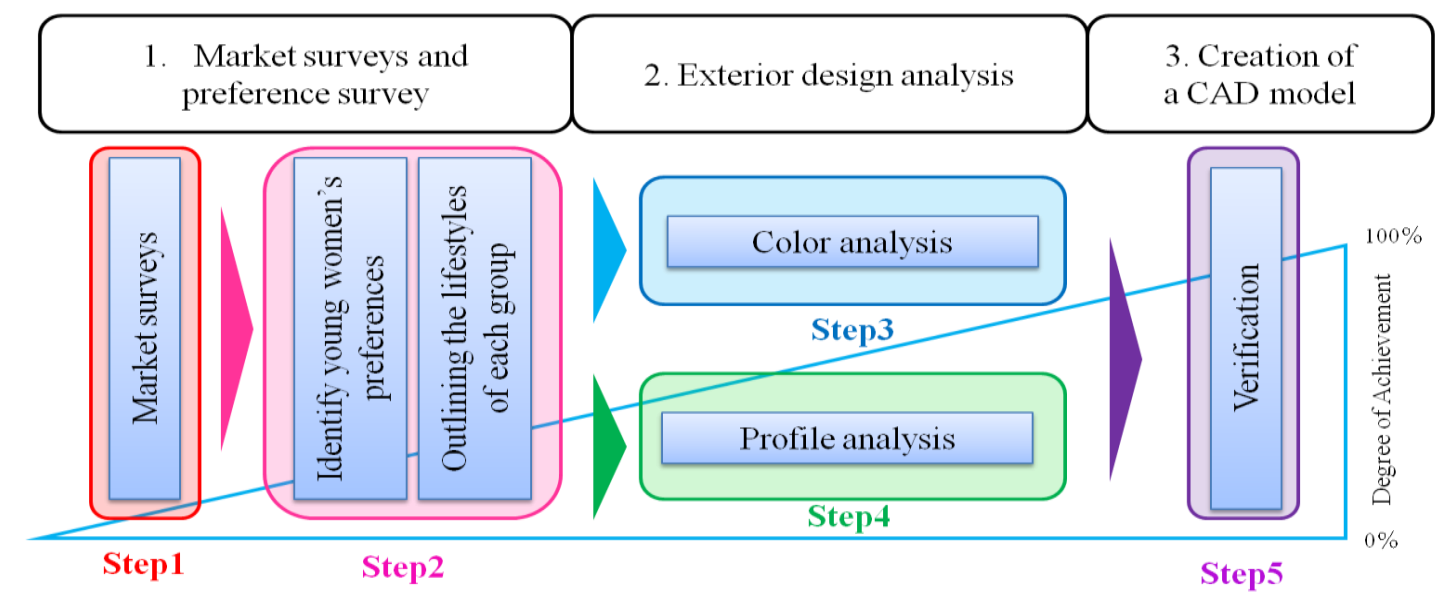

Figure 1: The A-VEDAM Model for Approaching Vehicle Exterior Design

Subjective survey sheets with color samples are created in step 3, and the results are used to pinpoint those colors that evoke the image words. In step 4, measurement data from the vehicle models used in the survey is compared to identify the body proportions that correspond to the image words.

\section{APPLICATION}

\section{Step 1: Market Surveys}

Interview surveys conducted at retail shops revealed that women in particular place high priority on harmony between form and color as well as the overall coordination of the design. It was also found that many women consider vehicles to be an expression of fashion tastes.

Observational surveys were also conducted in both an urban (the Ginza district of Tokyo) and suburban (the Tsurumai area in Aichi Prefecture) to identify which vehicles seemed attractive and left an impression on passersby when they drove by. The survey indicated that attractive cars were those that intuitively seemed stylish and also had a sense of luxury.

This certainly seemed to parallel fashion, so a goal was set to create an exterior design that harmonized color and form.

\section{Step 2: Collecting and Analyzing Women's Preferences}

\section{Creating a Subjective Survey Sheet}

The first task was to create a subjective survey sheet to identify the preferences of the target customers (women).

The subjective survey sheet consisted of five sections:

1. nine items assessing the person's interest in cars

2. nine items assessing preference for design images

3. eleven items assessing the respondent's lifestyle in terms of vehicle use

4. interests and hobbies

5. favorite magazines 
Items in the first three sections used a seven-point rating scale, while the last two sections were free response. This survey was aimed at women in their twenties, and answers were obtained from a total of 67 women.

\section{Using Collage Boards to Specify Preferences}

A cluster analysis was performed on the data collected in 5.2.1 to sort the preferences into groups. The types of clothes, handbags, mobile phones, magazines, and watches preferred by those in each group were arranged on into collages and attached to boards. Each board was then given a descriptive name.

This allowed preferences to be grouped into five categories - girlish, elegant, casual, trendy and boyish like those shown in Figure 2. As shown in Table 1, each board is given a single image word that best captures the style shown. Respondents then selected domestic and foreign vehicles from those seen during the crowd-watching phase that they subjectively thought matched the clothing on each collage board.

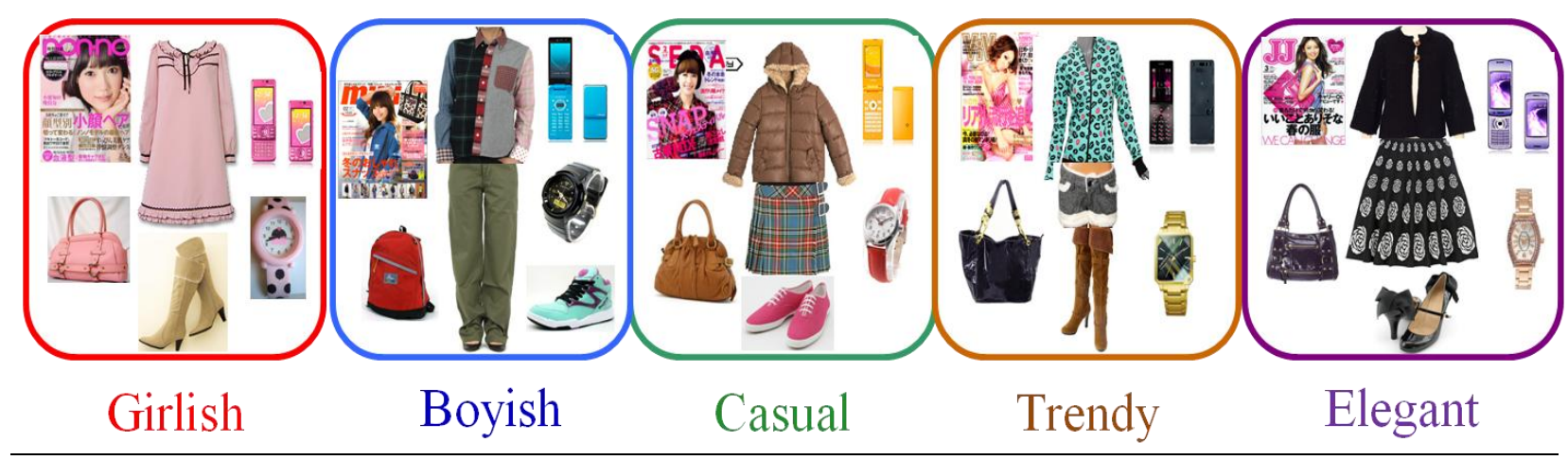

Figure 2: Collage Boards

Table 1: Key Image Words for each Preference Group

\begin{tabular}{|c|l|}
\hline $\begin{array}{c}\text { Preference } \\
\text { category }\end{array}$ & \multicolumn{1}{|c|}{ Key image words } \\
\hline Girlish & Cute, small, round \\
\hline Elegant & Luxury, high-end, stylish, chic \\
\hline Casual & Original, cute \\
\hline Trendy & Eye-catching, popular \\
\hline Boyish & Large, boxy, classic \\
\hline
\end{tabular}

No vehicles matched the "elegant" preference category. A principle component analysis performed in order to pinpoint the kinds of vehicles that would appeal to those in this category revealed that members of this group wanted a car that was luxurious, stylish, high-end, and chic. To target customers in the "elegant" category, a car that exemplified these characteristics needed to be developed.

\section{Step 3: Color Analysis}

In order to investigate the relationship between the image words preferred by young women in the "elegant" category and color, subjective color survey sheets were prepared and respondents were asked to report their impressions. A total of 60 colors were selected using a combined assortment of three factors: brightness, saturation, and hue. These 60 colors were sorted into six groups to create six different subjective color survey sheets shown in Figure 3. 


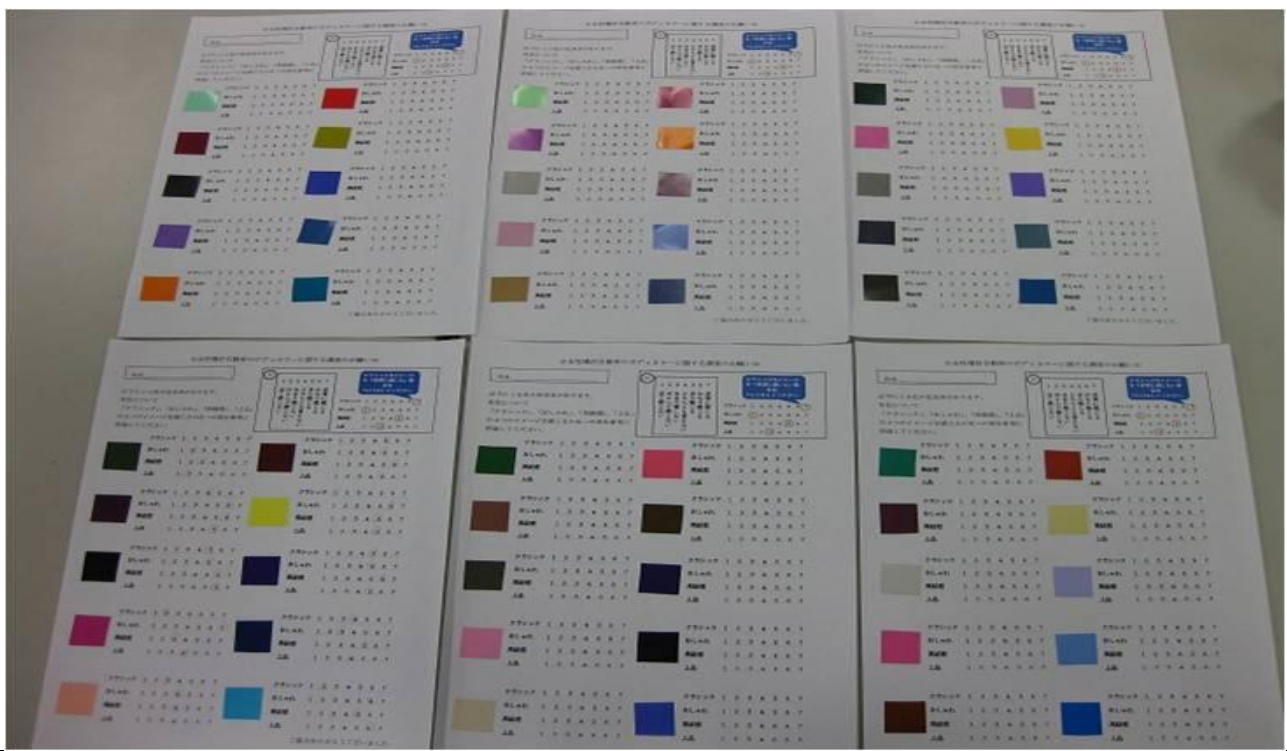

Figure 3: Subjective Color Survey Sheets

Each respondent was asked to select one of the six sheets at random, so that each person rated ten colors on a seven-point scale according to how much the color seemed luxurious, stylish, high-end, or chic. PANTONE color samples were used for the survey.

A principle component analysis was conducted on the results to identify how colors scored on two axes: luxurious/stylish and high-end/chic. The matrix chart in Figure 4 was created with a "luxury" and "high-end" axis to plot the scores from the seven-point scale. Another matrix chart was created with "stylish" and "chic" on the axes. As a result, the colors that best evoked the image words associated with a preference for "elegance" were determined. These are shown in Figure 5.

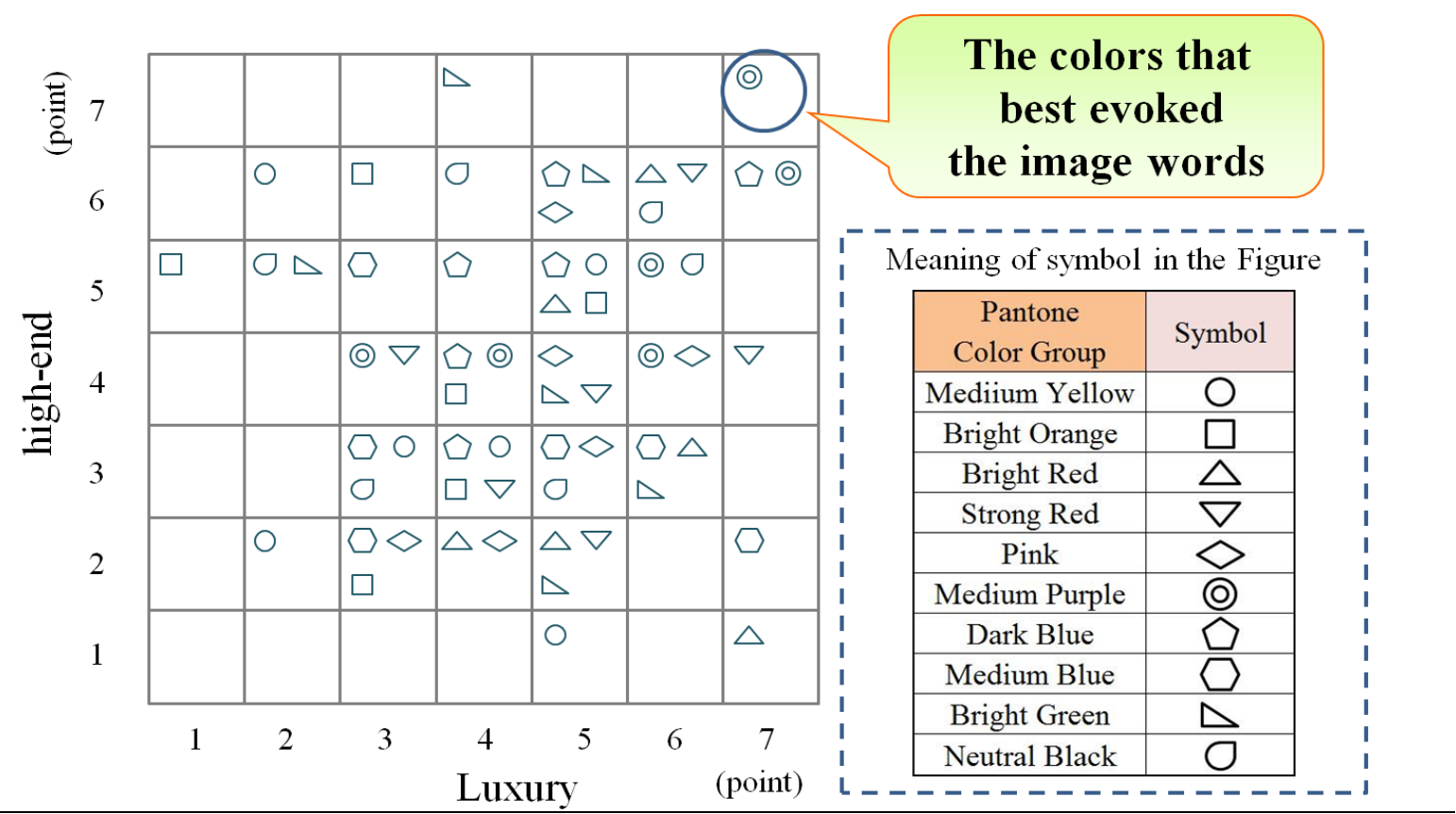

Figure 4: Color Matrix showing "Luxury" and "High-end" Axes 


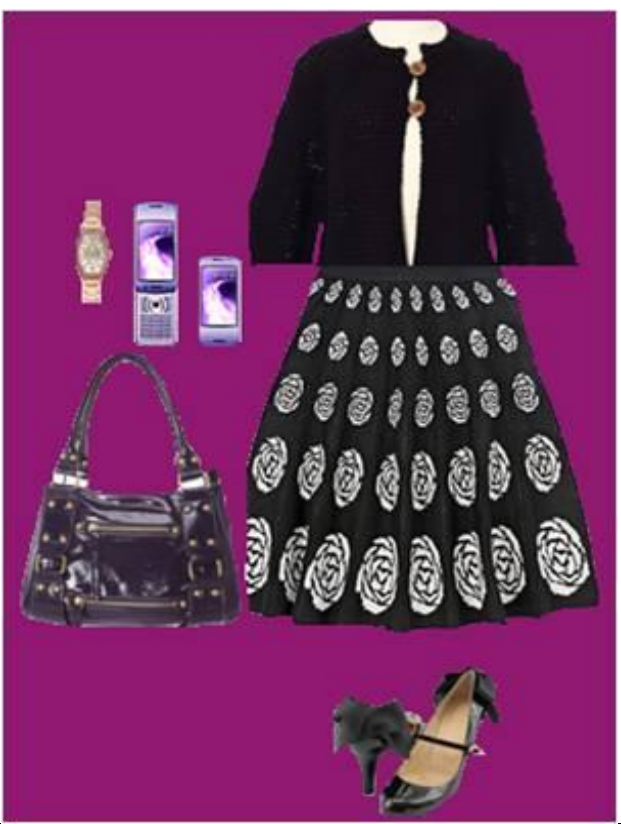

Figure 5: Colors that express "Elegance"

\section{Step 4: Profile Analysis}

Our approach to analyzing the profile design was first to identify the relationship between the exterior profiles of existing vehicles and image words using an exterior survey. Actual dimensional data for these vehicles was collected, and the results were used to arrive at a profile design that would satisfy a preference for elegance. Seven models currently sold in Japan were used: the Vitz, bB, Passo, Cube, March, Fit, and Demio.

Survey respondents were shown pictures of the front, side, and rear of these seven vehicles, and asked to rate them on a seven-point scale according to how well they seemed to cpture each of the four image words(luxurious, stylish, high-end, and chic). Various measurement data was then collected from body measurement drawings. Each of the measurements was divided by the total width of the vehicle to generate proportional data that could be used for direct comparison regardless of the size of the vehicle.

Images of each vehicle were evaluated along with the proportional data, revealing how the proportion modifications to the front, side, and rear of the vehicles affected the qualities expressed by the four image words. A summary of these findings is shown in Table 2.

Table 2: Effect of Proportion Modifications on Each Image Word

\begin{tabular}{|c|c|}
\hline Image word & Change in proportion \\
\hline Luxurious & $\begin{array}{c}\text { Larger windshield angles and } \\
\text { wider overall }\end{array}$ \\
\hline Stylish & $\begin{array}{c}\text { Shorter distance between the } \\
\text { headlights, narrower overall }\end{array}$ \\
\hline Chic & $\begin{array}{c}\text { Shorter height and narrower } \\
\text { overall }\end{array}$ \\
\hline High-end & $\begin{array}{c}\text { Wider windshield and wider } \\
\text { overall }\end{array}$ \\
\hline
\end{tabular}




\section{VERIFICATION}

Based on the information gathered in this study, a vehicle was designed using 3D-CAD that captured the luxurious, stylish, high-end, and chic qualities preferred by those with "elegant" tastes (figure omitted). When those in the "elegant" group were again polled about the design model, they indeed found that the image left an impression on them. In this way, the effectiveness of the A-VEDAM was verified.

\section{CONCLUSION}

Even as customer needs in general become increasingly diverse, the preferences of young women are thought to be particularly varied and difficult to pinpoint. Today's women place priority on color when purchasing a vehicle, and it has been shown that these color choices have strong links to clothing and fashion. The authors have thus concluded that creating the vehicle designs that women want requires matching women's preferences in terms of lifestyle and fashion (clothing). In other words, it is essential to generate a sense of "customer delight".

A collage board was then put together to capture the elegant tastes of the target group. A sujective survey sheet was created, and it was determined that this group prioritized vehicles that presented a luxurious, stylish, highend, and chic image. Colors were selected that would evoke these qualities and match the fashion choices of those with elegant tastes. Next, in order to generate a design that would match these colors, an analysis of vehicle proportions was done to figure out how actual vehicles could be made to align more closely with the four image words preferred by those with elegant tastes.

Next, in order to bridge the gap between customer evaluations and actual vehicle designs, 3D-CAD software was used to generate vehicle designs that fit well with the colors. In other words, a vehicle design with integrated form and color was achieved.

\section{AUTHOR INFORMATION}

Hiroki Asami is a graduate student of the College of Science and Engineering at Aoyama Gakuin University.

Hideaki Owada is a graduate student of the College of Science and Engineering at Waseda University.

Yuka Murata has received her Bachelor of Engineering degree from the College of Science and Engineering at Aoyama Gakuin University.

Shohei Takebuchi is a graduate student of the College of Science and Engineering at Aoyama Gakuin University.

Kakuro Amasaka is a Professor in the College of Science and Engineering at Aoyama Gakuin University, Japan. He received his Ph.D. degree in Precision Mechanical and System Engineering, Statistics and Quality Control at Hiroshima University in 1997. His current research and teaching interests are in the general area of production engineering. In particular, he is interested in Science TQM and New JIT. He is the member of POMS and EUROMA and is the chairman of JOMSA of Japan now. Email: amasaka@hn.catv.ne.jp

\section{REFERENCES}

1. Amasaka, K., A. Nagaya and W. Shibata, Studies on Design SQC with the Application of Science SQC Improving of Business Process Method for Automotive Profile Design, Japanese Journal of Sensory Evaluations, Vol.3, No.1, pp.21-291, 1999.

2. Amasaka, K., and A. Nagaya, Engineering of the New Sensitivity in the Vehicle, Development of the Articles over the Sensitivity, International Journal of Kansei Engineering, Nihon Shuppan Service Press, pp.55-72, 2002. (in Japanese)

3. Amasaka, K., Constructing a Customer Science Application System "CS-CIANS" - Development of a Global Strategic Vehicle Lexus Utilizing New JIT-, WSEAS Transactions on Business and Economics, Issue3, Vol.2, pp.135-142, 2005. 
4. Amasaka, K., Development of "Science TQM", International Journal of Production Research, Vol.42, pp.3691-3706, 2004.

5. Amasaka, K., The Validity of "TDS-DTM", A Strategic Methodology of Merchandise - Development of New JIT, Key to the Excellence Design "LEXUS"-, The International Business \& Economics Research Journal, Vol.6, No.11, pp.105-115, 2007.

6. Ando, T., M. Yamaji and K. Amasaka, A Study on Construction of Automobile Design Concept Support Methods - Visualization of Form and Customer Sensibility Utilizing Design CAD-, The Japanese Society for Quality Control, The 38th Annual Conference, Tokyo, Japan, pp.177-180, 2008. (in Japanese)

7. Asami, H., T. Ando, M. Yamaji and K. Amasaka, A Study on Automobile Form Design Support Method “AFD-SM”, Journal of Business \& Economics Research, Vol.8, No.11,pp13-19. 2010.

8. $\quad$ Mori, N., Left brain Designing, Kaibundou Syuppan, 1996. (in Japanese)

9. Okabe, Y., M. Yamaji and K. Amasaka, Research on the Automobile Package Design Concept Support Methods "CS-APDM", Proceedings of the $11^{\text {th }}$ Annual International Conference on Industrial EngineeringTheory, Application and Practice, Nagoya, Japan, pp.268-273, 2007.

10. Yamaji, M., and K. Amasaka, Intelligence Design Concept Method Utilizing Customer Science, The Open Industrial and Manufacturing Engineering Journal, Vol.2, pp.21-25, 2009. 